\title{
Clemens Trautmann
}

\section{Europäisches Kollisionsrecht und ausländisches Recht im nationalen Zivilverfahren}

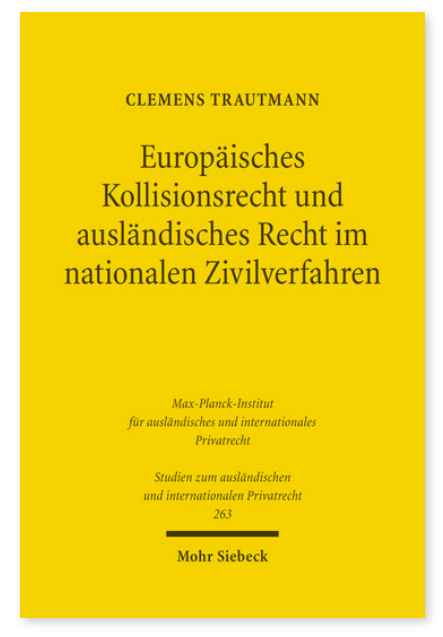

2011. XXVIII, 483 Seiten. StudIPR 263

ISBN 978-3-16-151448-7

DOI 10.1628/978-3-16-151448-7

eBook PDF 109,00 €

ISBN 978-3-16-150483-9

fadengeheftete Broschur 109,00€
Mit der Europäisierung des internationalen Privatrechts verfolgt die Union das Ziel , dass ein Streitfall - unabhängig vom Gerichtsstand - in allen Mitgliedstaaten nach demselben Recht beurteilt wird. Ob dies in der Praxis gelingt, hängt allerdings von den nationalen Verfahrensregeln zur Anwendung und Ermittlung ausländischen Rechts ab, die in den Mitgliedstaaten sehr heterogen ausgestaltet sind. Clemens Trautmann untersucht die Verfahrensregeln der wichtigsten europäischen Jurisdiktionen auf ihre Vereinbarkeit mit dem Unionsrecht und entwickelt auf der Basis einer rechtsvergleichenden und unionsrechtlichen Analyse Lösungen für die wesentlichen Problemfelder: fakultatives Kollisionsrecht, stillschweigende Rechtswahl im Prozess, Feststellung von Anknüpfungstatsachen, Einführung ausländischen Rechts in Rechtsmittelinstanzen sowie in Eilverfahren, Offenlassen der kollisionsrechtlichen Entscheidung, Verteilung der Ermittlungslasten und Nichtermittelbarkeit ausländischen Rechts.

Clemens Trautmann Geboren 1977; Studium der Musik an der Musikhochschule Lübeck und der Juilliard School New York sowie der Politikwissenschaft an der Columbia University; Studium der Rechtswissenschaft an der Universität Hamburg; 2006 und 2008 juristische Staatsexamina; 2010 Promotion sowie Promotionspreis der Fakultät für Rechtswissenschaft der Universität Hamburg; ab 2009 Assistent des Vorstandsvorsitzenden und ab 2011 International Licensing Director der Axel Springer AG.
Jetzt bestellen:

https://mohrsiebeck.com/buch/europaeisches-kollisionsrecht-und-auslaendisches-recht-im-nationalen-zivilverfahren9783161514487?no_cache=1

order@mohrsiebeck.com

Telefon: +49 (0)7071-923-17

Telefax: +49 (0)7071-51104 